\title{
The Radiographic Features of Mycobacterium Malmoense Infection
}

\author{
Mwaffaq El Heis*, Maha Gharaibeh, Mammon Al-Omari and Ruba Khasawneh \\ Radiology Department, Jordan University of Science and Technology, Jordan
}

Received: April 09, 2018; Published: April 17, 2018

*Corresponding author: Mwaffaq El Heis, Radiology department, Jordan University of Science and Technology, Jordan, Tel: 962799051501;

Email: elheis@hotmail.com

\begin{abstract}
Mycobacterium malmoense is a rare infection with increasing prevalence since its first reported cases. It is not easy to be diagnosed. The objective of this study was to report our experience in managing this infection. A total of 24 cases were included from Jordan and United Arab Emirates. Our finding showed that in M. malmoense thick-walled cavitating lesions are common especially in the upper lobes. In our series, there was almost equal distribution of unilateral and bilateral disease. Underlying fibrosis was commonly present with pleural effusions rarely seen. Middle and lower lobe involvement was rare. The findings show the diverse range of radiological appearances seen in patients with nontuberculous mycobacterial infections. Taken together, although the appearances are non-specific, an awareness of the varied presentations of these infections is important in order to expedite the correct diagnosis and the commencement of appropriate therapy.
\end{abstract}

Keywords: Mycobacterium malmoense; Pulmonary; Cavities; CTscan; X-Ray Radiography

\section{Introduction}

Mycobacterium malmoense is known as a slow- growing nontuberculous mycobacterium (NTM) and leads to human infection mainly among patients who are suffering from cellular immunity conditions [1] Although M. Malmoense mainly causes pulmonary infections, but extra pulmonary infections including cervical lymphadenitis and tenosynovitis are likely to exist [2]. M.malmoense is considered as an atypical mycobacterial strain that has been discovered in Sweden since 1954 [3] although the incidence of $M$. malmoenseis still rare, it has been shown to increase since the $1980 \mathrm{~s}$ [4]. It has been noted that the majority of patients with M. malmoense infections have been affected by lung disease that impacts immune system including chronic obstructive pulmonary disease (COPD) [3]. According to the study of Hoefsloot, the occurrence of infection is significantly associated with contaminated water or soil.

It is of great importance to manage M. malmoense infections in terms of diagnosis at appropriate time and administration of appropriate treatment [3]. In their study, [5] showed the difficulties in diagnosis of pulmonary infection due to M. malmoense, a matter that impacts the appropriate treatment. They reported a case with delayed diagnosis because of thinking of pulmonary Mycobacterium tuberculosis infection. We have showed our experience of this infection in north Jordan and United Arab Emirates, and report the radiological findings in 24 patients seen over a 4 years period (Between January 2012 and December 2016).

\section{Methods}

A retrospective study design was conducted to review chest radiographs including CT scan and X-ray radiographs in Jordan and United Arab Emirates. There were 24 cases positive for this infection. The data for these cases were collected including age and gender. A radiographic description was give and summarized in tables and figures. Data was presented as frequencies and percentages for categorized variables, and as means for continuous variables.

\section{Results}

Table 1: Demographic variables of study participants.

\begin{tabular}{|c|c|c|}
\hline Variable & Frequency (N) & Percentage (\%) \\
\hline Gender: & 16 & $66.67 \%$ \\
- Male & 8 & $33.33 \%$ \\
- Female & 53 years & - \\
\hline Age (2-68 years): & 24 & $100 \%$ \\
- Mean & & \\
\hline
\end{tabular}

As shown in Table 1, the study included 24 patients of whom two thirds $(66.67 \%)$ were males. The mean age was 53 years in the range of 2-68 years. The chest X-ray showed that there was no pleural effusion, $24 \%$ had emphysema, $50 \%$ had fibrosis, about 
$17 \%$ had well circumscribed opacity, about $17 \%$ had air space shadowing, about $13 \%$ developed pleural disease, and about $4 \%$ developed primary focus (Table 2) and (Figures 1-4). A total of 8 patients out of 24 patients had CT scan of chest. Consolidation was exhibited in $25 \%$ of patients, nodes (mediastinum) were developed in $12.5 \%$ of patients, Pleural thickening in $12.5 \%$ of patients, and pleural effusion in $0 \%$ of patients.

Table 2: Radiological appearances on chest X-RAY.

\begin{tabular}{|c|c|c|}
\hline Variable & Frequency (N) & Percentage (\%) \\
\hline Pleural Effusion & 0 & $0 \%$ \\
\hline Emphysema & 6 & $24 \%$ \\
\hline $\begin{array}{c}\text { Loss of Volume/ } \\
\text { Fibrosis }\end{array}$ & 12 & $50 \%$ \\
\hline $\begin{array}{c}\text { Well circumscribed } \\
\text { opacity }\end{array}$ & 4 & $16.67 \%$ \\
\hline Air Space Shadowing & 4 & $16.67 \%$ \\
\hline Pleural Disease & 3 & $12.50 \%$ \\
\hline Primary Focus & 1 & $4.17 \%$ \\
\hline
\end{tabular}

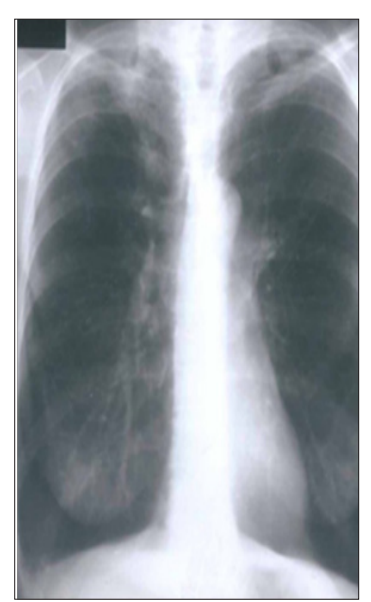

Figure 1: Chest radiology showing focal consuldation in Rt Apex.

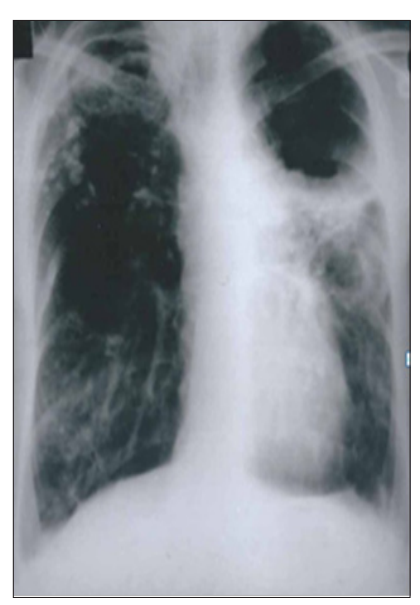

Figure 2: Chest $X$-ray showing large left upper lobe cavity. Note changes also in the RT upper lobe.

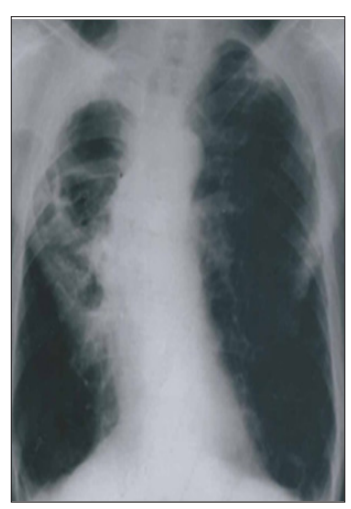

Figure 3: Chest Radiology showing emphysematous changes with RT upper lobe fibrosis and cavitation.

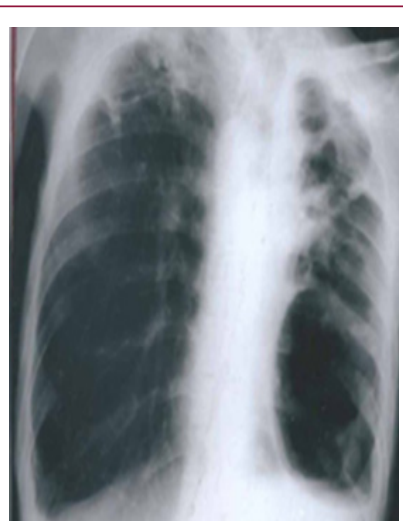

Figure 4: Chest radiograph showing RT upper lobe cavitation and left upper lobe cavitation/consolidation.

Table 3: Radiological appearance on $\mathrm{CT}$ chest $(\mathrm{N}=8)$.

\begin{tabular}{|c|c|c|}
\hline Variable & Frequency (N) & Percentage (\%) \\
\hline Consolidation & 2 & $25 \%$ \\
\hline Nodes (Mediastinum) & 1 & $12.50 \%$ \\
\hline Pleural Thickening & 1 & $12.50 \%$ \\
\hline Pleural Effusion & 0 & 0 \\
\hline Fibrosis & 3 & $37.50 \%$ \\
\hline Emphysema & 3 & $37.50 \%$ \\
\hline Cavities & 3 & $37.50 \%$ \\
\hline Focal Abnormalities & 2 & $25 \%$ \\
\hline Interstitial Thickening & 1 & $12.50 \%$ \\
\hline Bronchiectasis & 2 & $25 \%$ \\
\hline
\end{tabular}

The results also showed that $37.5 \%$ of patients developed fibrosis, emphysema in $37.5 \%$, cavities in $37.5 \%$, focal abnormalities in $25 \%$, interstitial thickening in $12.5 \%$, and bronchiectasis in $25 \%$ of patients (Table 3) and (Figures 5-8). Cavities related variables included number of cavities, size of cavities, and wall thickness. In $90 \%$ of patients, the number of cavities was more two cavities. In $80 \%$ of patients, the size of cavity was more than $2 \mathrm{~cm}$. The majority of cases (80\%) developed thick wall cavities (Table 4). As it can be seen in Table 5, pulmonary abnormalities were unilateral (41.77\%), bilateral (58.33\%), right upper lobe (37.5\%), left (29.17\%), right- 
apices $(20.83 \%)$, and each of middle lobe and right lower lobe (4.17\%).

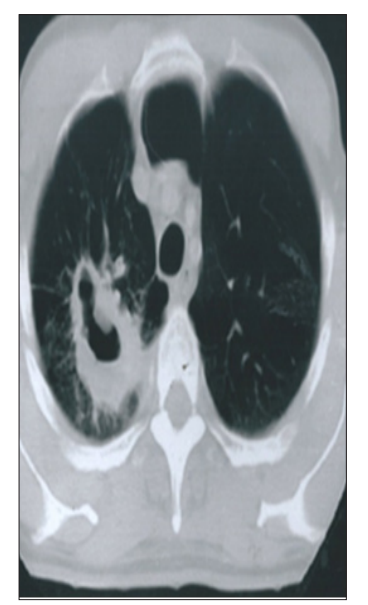

Figure 5: Ct Chest showing think walled cavity in the RT upper lobe.

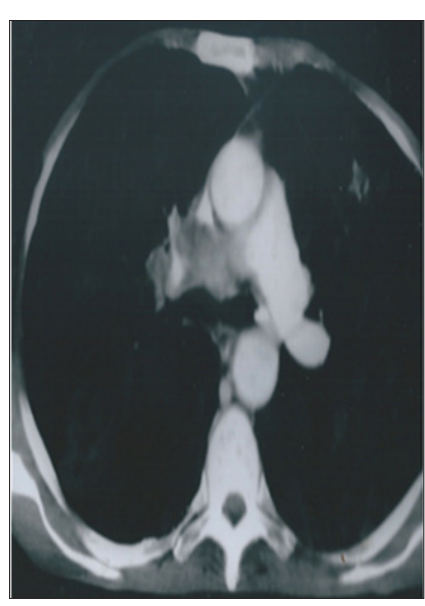

Figure 6: CT chest demonstrating pretracheal lymph node.

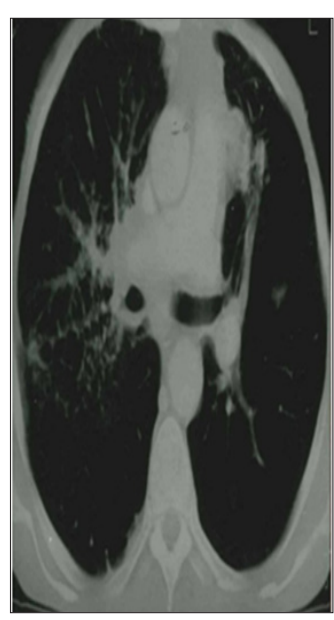

Figure 7: CT chest showing interstitial thickening in the RT lung.

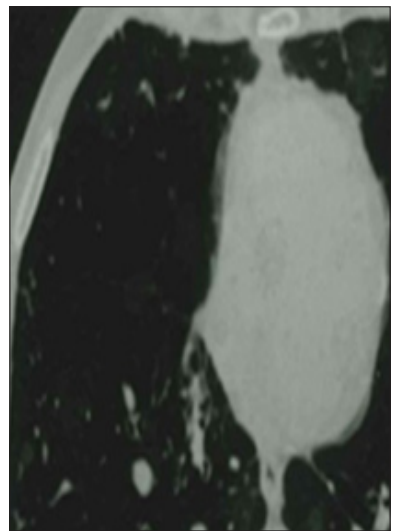

Figure 8: CT chest showing bilateral bronchiectatic changes.

Table 4: Cavities related variables.

\begin{tabular}{|c|c|c|}
\hline No of cavities & Frequency (N) & Percentage (\%) \\
\hline No of cavities: & 1 & $10 \%$ \\
-1 & 5 & $50 \%$ \\
$-2-3$ & 4 & $40 \%$ \\
$->3$ & 2 & $20 \%$ \\
\hline Size of cavity (cm): & 3 & $30 \%$ \\
$02-$ Apr & 5 & $50 \%$ \\
$>4$ & 8 & $80 \%$ \\
\hline Wall thickness: & 2 & $20 \%$ \\
\hline - Thick & & \\
\hline - Thin & & \\
\hline
\end{tabular}

Table 5: Distribution of pulmonary abnormalities.

\begin{tabular}{|c|c|c|}
\hline Variable & Frequency (N) & Percentage (\%) \\
\hline Unilateral & 10 & $41.77 \%$ \\
\hline Bilateral & 14 & $58.33 \%$ \\
\hline Apices-RT & 5 & $20.83 \%$ \\
\hline Lt & 7 & $29.17 \%$ \\
\hline Upper Lobe-RT & 9 & $37.50 \%$ \\
\hline Middle Lobe & 1 & $4.17 \%$ \\
\hline Lower Lobe-RT & 1 & $4.17 \%$ \\
\hline
\end{tabular}

\section{Discussion}

The present study reported our experience in diagnosing the infection of $M$. malmoense through X-ray radiation and CT scan. A total of 24 cases were included. Although it is not common to find $M$. malmoensein clinical practice, there is still a possibility to be found. Our data showed that M. malmoense caused several pulmonary lesions including emphysema, pleural effusion, and pleural disease. These findings are consistent with previous studies [3]. Using CT scan showed multiple with sizes more than $2 \mathrm{~cm}$ in $80 \%$ of cases. These findings do agree with those of Evans et al. [3] who reported $6 \mathrm{~cm}$ cavity size in about $50 \%$ of cases. 


\section{Conclusion}

Our finding showed that in M. malmoense thick-walled cavitating lesions are common especially in the upper lobes. In our series, there was almost equal distribution of unilateral and bilateral disease. Underlying fibrosis was commonly present with pleural effusions rarely seen. Middle and lower lobe involvement was rare. The findings show the diverse range of radiological appearances seen in patients with non-tuberculous mycobacterial infections. Although the appearances are non-specific, an awareness of the varied presentations of these infections is important in order to expedite the correct diagnosis and the commencement of appropriate therapy $[6,7]$.

\section{References}

1. Rebecca van Grootveld, Hans U Scherer, Elke EM Peters, André Gaasbeek, Sandra M Arend, et al. (2018) Tenosynovitis caused by Mycobacterium malmoense in two kidney transplant recipients and review of the literature. Transpl Infect 20(1).
2. Hoefsloot W, Boeree MJ, van Nieuwkoop C, Bernards AT, Savelkoul PH, et al. (2012) No human transmission of Mycobacterium malmoense in a perfect storm setting. Eur Respir J 40(6): 1576-1578.

3. Eric Abston, Harrison Farber (2018) Pulmonary Cavity From Mycobacterium malmoense in an HIV-Infected Patient: Complicated by Bronchopleural Fistula. Open Forum Infectious Diseases 5(2).

4. Warren NG, Body BA, Silcox VA, Matthews JH (1984) Pulmonary disease due to Mycobacterium malmoense. J ClinMicrobiol 20: 245-247.

5. Huet D, Godbert B, Hermann J, Zordan JM, Chabot F, et al. (2016) Pulmonary infection with Mycobacterium malmoense. Difficulties in diagnosis and treatment. Revue des Maladies Respiratoires 34(3): 257261.

6. AJ Evans, AJ Crisp, A Colville, SA Evans, ID Johnston (1993) Pulmonary infections caused by Mycobacterium malmoense and Mycobacterium tuberculosis: comparison of radiographic features. American Journal of Roentgenology 161(4): 733-737.

7. Hoefsloot W, Boeree MJ, van Ingen J, Bendien S, Magis C, et al. (2008) the rising incidence and clinical relevance of Mycobacterium malmoense: A review of literature. Int J Tuberc Lung Disease 12(9): 987-993.

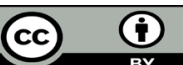

This work is licensed under Creative Commons Attribution 4.0 License

Submission Link: https://biomedres.us/submit-manuscript.php

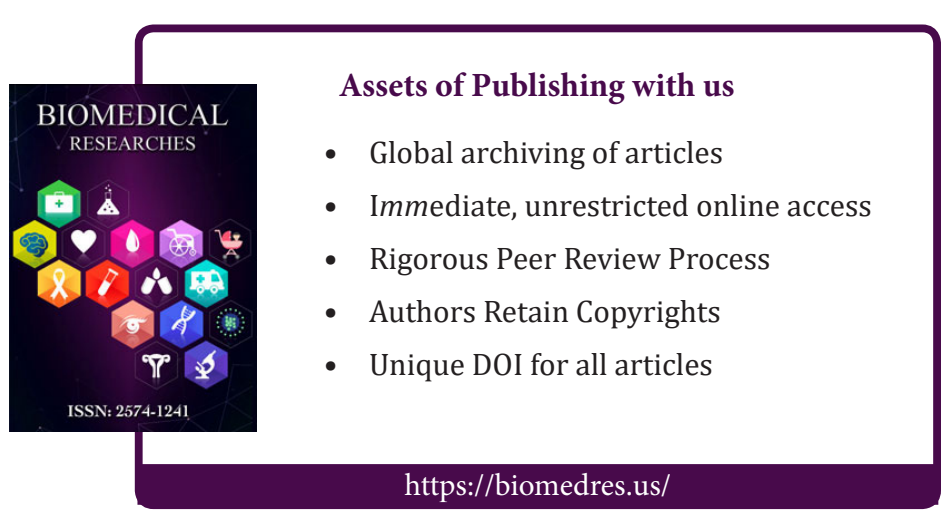

